УДК 666.974.2

Канд. техн. наук А.Н. Корогодская, д-р техн. наук Г.Н. Шабанова (НТУ «ХПI»)

A.N. Korogodska, G.N. Shabanova

\title{
ОГНЕУПОРНЫЙ БЕТОН НА ОСНОВЕ АЛЮМОБАРИЕВОГО ХРОМСОДЕРЖАЩЕГО ЦЕМЕНТА
}

\section{REFRACTORY CONCRETE BASED ON ALUMINUM-BARIUM CEMENT CONTAINING CHROMIUM}

Интенсификация производственных тепловых процессов в различных отраслях науки и техники требует создания новых конструкционных материалов, которые способны кроме воздействия высоких температур противостоять агрессивному воздействию расплавов, растворов электролитов, высокого давления. Огнеупорные материалы, существующие в настоящее время, преимущественно являются штучными изделиями и требуют дополнительного шовного скрепления, что значительно снижает срок эксплуатации. Замена искусственных огнеупоров на монолитную бесшовную бетонную футеровку позволяет выполнить все необходимые требования по эксплуатационной надежности теплового агрегата [1-3].

Основным направлением при разработке технологических решений образования безобжиговых огнеупоров является подбор оптимального качественного и вещественного состава заполнителя, обеспечивающего формирование при нагреве до температуры эксплуатации необходимых физикомеханических и технических характеристик рабочего слоя футеровки.

В качестве связки при производстве таких огнеупоров чаще всего используются алюминатные цементы, а в последнее время - шпинельные цементы, в том числе и на основе алюминатов бария. 
Шпинельные цементы относятся к высокоогнеупорным, быстротвердеющим высокопрочным вяжущим [4].

Анализ литературных данных показывает, что получение бетонов с использованием шпинельных цементов на основе алюминатов и хромитов бария с комплексом заданных эксплуатационных характеристик является

актуальной проблемой.

Большую заинтересованность составляет изучение влияния количественного и качественного соотношения алюминатов и хромитов бария на физико-механические и технические свойства получаемых цементов (табл. 1).

Таблица 1

Химический состав и физико-механические свойства алюмобариевых хромсодержащих цементов

\begin{tabular}{|c|c|c|c|c|c|c|c|c|c|c|}
\hline \multirow[t]{2}{*}{$\begin{array}{l}\text { № } \\
\Pi / \Pi\end{array}$} & \multicolumn{3}{|c|}{$\begin{array}{c}\text { Химический состав, } \\
\text { масс. \% }\end{array}$} & \multirow[t]{2}{*}{ В/Ц } & \multicolumn{2}{|c|}{$\begin{array}{c}\text { Сроки } \\
\text { схватывания, } \\
\text { час-мин }\end{array}$} & \multicolumn{3}{|c|}{$\begin{array}{c}\text { Предел прочности при } \\
\text { сжатии, МПа, в возрасте, } \\
\text { сут }\end{array}$} & \multirow[t]{2}{*}{$\begin{array}{l}\mathrm{T}_{\text {плавления, }} \\
{ }^{\circ} \mathrm{C}\end{array}$} \\
\hline & $\mathrm{BaO}$ & $\mathrm{Al}_{2} \mathrm{O}_{3}$ & $\mathrm{Cr}_{2} \mathrm{O}_{3}$ & & начало & конец & 3 & 7 & 28 & \\
\hline 1 & 73,6 & 4 & 22,4 & 0,22 & $2-05$ & $3-20$ & 10,2 & 12,3 & 18,6 & 1424 \\
\hline 2 & 72,1 & 8 & 19,9 & 0,25 & $2-00$ & $3-05$ & 10,2 & 14,4 & 26,3 & 1460 \\
\hline 3 & 70,6 & 12 & 17,4 & 0,27 & $1-20$ & $2-55$ & 10,2 & 18,6 & 22,4 & 1548 \\
\hline 4 & 69,1 & 16 & 14,9 & 0,33 & $1-00$ & $2-40$ & 10,2 & 28,6 & 30,6 & 1616 \\
\hline 5 & 67,6 & 20 & 12,4 & 0,23 & $0-35$ & $2-30$ & 16,3 & 30,6 & 46,9 & 1672 \\
\hline 6 & 66,1 & 24 & 9,9 & 0,24 & $0-25$ & $1-50$ & 22,5 & 36,7 & 44,1 & 1716 \\
\hline 7 & 64,5 & 28 & 7,5 & 0,23 & $0-25$ & $1-40$ & 28,6 & 38,7 & 53,9 & 1760 \\
\hline 8 & 63,0 & 32 & 5,0 & 0,22 & $0-25$ & $0-55$ & 75,4 & 87,7 & 90,2 & 1790 \\
\hline 9 & 61,5 & 36 & 2,5 & 0,21 & \multicolumn{2}{|c|}{ Мгновенно } & 31,2 & 46,7 & 48,9 & 1816 \\
\hline
\end{tabular}

Тщательное смешивание и помол исходных сырьевых компонентов проводились в лабораторной шаровой мельнице до полного прохода через сито №006. Полученный шлам высушивался при температуре $100-110^{\circ} \mathrm{C}$ и брикетировался на гидравлическом прессе. Обжиг образцов проводился в криптоловой печи при температуре $1320-1380^{\circ} \mathrm{C}$ в зависимости от фазового состава с изотермической выдержкой при максимальной температуре 3 час. Обжиг производился в тиглях под слоем криптола для исключения окисления $\mathrm{Cr}^{3+} \rightarrow \mathrm{Cr}^{6+}$. После обжига образцы измельчались до полного прохода через сито № 006. Определение физикомеханических свойств производилось в соответствии с методикой малых образцов Стрелкова М.И. [5].

В результате физико-механических испытаний установлено, что полученные цементы относятся к воздушным вяжущим материалам с водоцементным отношением от 0,22 до 0,$33 ;$ являются быстротвердеющими (начало схватывания от 25 мин до 2 час 5 мин, конец схватывания от 55 мин до 3 час 20 мин); быстротвердеющими (прочность при сжатии после 2 сут твердения составляет от 10,0 до 75,0 МПа); высокопрочными (прочность при сжатии в возрасте 28 сут от 18,0 до 90,0 МПа) с высокими температурами плавления (от 1424 до $1816^{\circ} \mathrm{C}$ ). Наиболее перспективным, на наш взгляд, является состав № 8 . 
Клинкер цемента оптимального состава был исследован с помощью ренгенофазового метода анализа [6]. Установлено, что основными фазами полученного алюмобариевого хромсодержащего цемента являются $\mathrm{BaAl}_{2} \mathrm{O}_{4}\left(\mathrm{~d} \cdot 10^{-10}=4,516 ; 4,40 ; 4,022 ; 3,155\right.$; 2,$608 ; 2,503 ; 2,459 ; 2,262 ; 2,245 ; 2,199$;
2,$012 ; 1,978 ; 1,951 ; 1,792 ; 1,711 ; 1,64 ; 1,594$; 1,578 м) и $\mathrm{Ba}_{3} \mathrm{Cr}_{2} \mathrm{O}_{6}\left(\mathrm{~d} \cdot 10^{-10}=4,40 ; 3,19\right.$; 2,$421 ; 2,012 ; 1,951 ; 1,64$ м). В остаточных количествах присутствует трехкомпонентное соединение $\mathrm{Ba}_{4} \mathrm{Al}_{2} \mathrm{Cr}_{2} \mathrm{O}_{10}$ $\left(\mathrm{d} \cdot 10^{-10}=3,411 ; 2,933 ; 2,827 ; 2,662 ; 2,375\right.$ м). Рентгенограмма клинкера полученного цемента приведена на рис. 1.

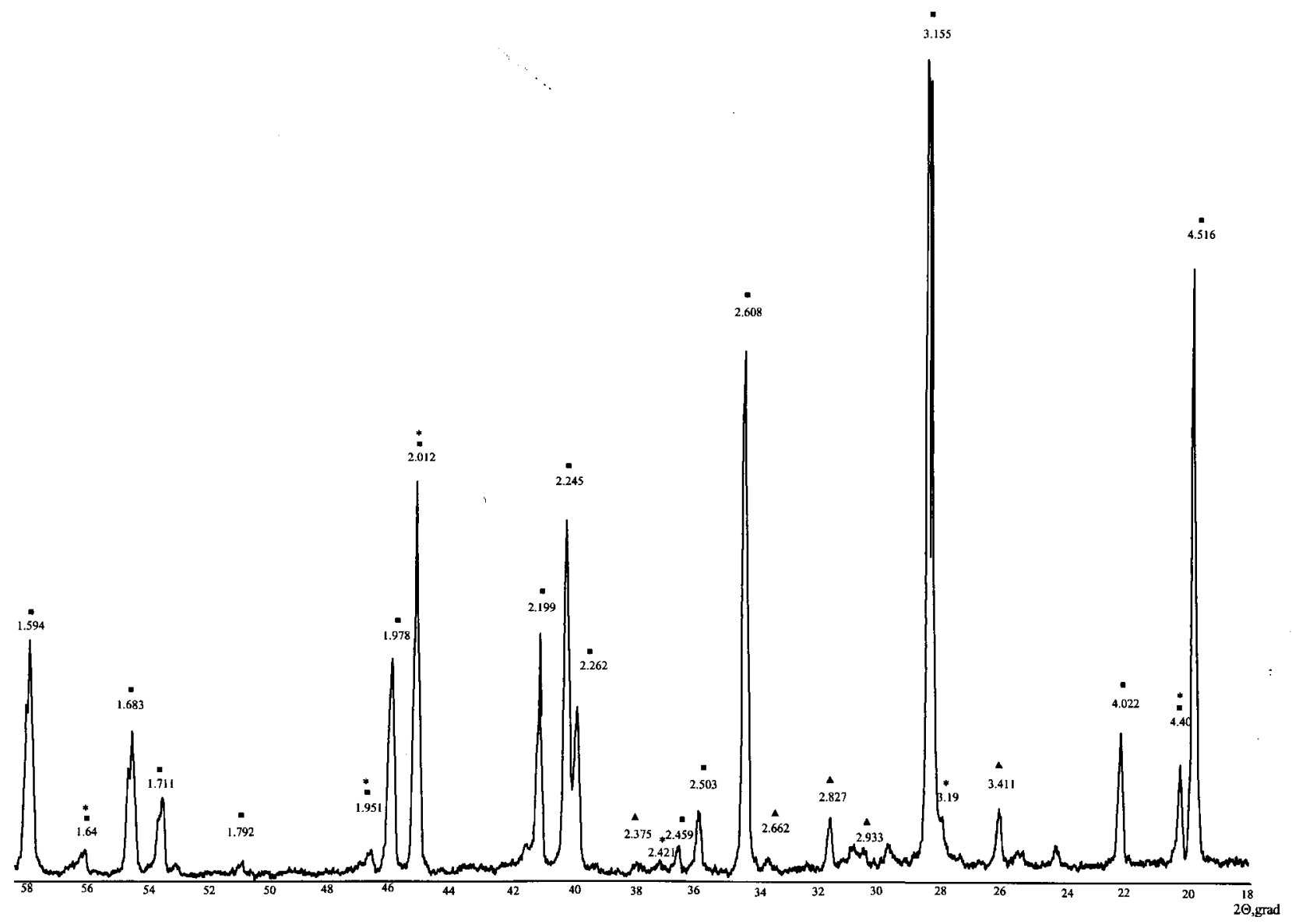

Рис. 1. Рентгенограмма клинкера алюмобариевого хромсодержащего цемента оптимального состава

Таким образом установлено, что основой клинкера цемента оптимального состава является моноалюминат бария и трехбариевый хромит.

С учетом субсолидусного строения системы $\mathrm{BaO}-\mathrm{Al}_{2} \mathrm{O}_{3}-\mathrm{Cr}_{2} \mathrm{O}_{3}$ компоненты цемента и корунд взаимодействуют во всем интервале температур, что определяет невозможность использования данного материала в качестве заполнителя для огнеупорных бетонов [7]. В связи с этим было предположено, что в качестве заполнителя может быть использован электроплавленный периклаз.

С помощью известных термодинамических данных для периклаза была рассчитана вероятность сосуществования основных компонентов алюмобариевого хромсодержащего цемента с $\mathrm{MgO}$ в соответсвии с реакциями:

1) $\mathrm{BaAl}_{2} \mathrm{O}_{4}+\mathrm{MgO}=\mathrm{MgAl}_{2} \mathrm{O}_{4}+\mathrm{BaO}$;

2) $\mathrm{Ba}_{3} \mathrm{Cr}_{2} \mathrm{O}_{6}+\mathrm{MgO}=\mathrm{MgCr}_{2} \mathrm{O}_{4}+3 \mathrm{BaO}$.

Результаты расчетов приведены в табл. 2 . 
Термодинамическая оценка энергии Гиббса реакций взаимодействия цемента с $\mathrm{MgO}$

\begin{tabular}{|c|c|c|c|c|c|c|c|}
\hline \multirow{2}{*}{$\begin{array}{c}\text { Номер } \\
\text { реакции }\end{array}$} & \multicolumn{5}{|c|}{ Величина свободной энергии Гиббса, кДж/моль, при температуре, К } \\
\cline { 2 - 7 } & 800 & 1000 & 1200 & 1400 & 1600 & 1800 & 2000 \\
\hline 1 & 76,5 & 74,2 & 71,9 & 69,5 & 67,0 & 64,7 & 62,5 \\
\hline 2 & 107,5 & 100,0 & 92,6 & 85,7 & 79,7 & 74,8 & 71,2 \\
\hline
\end{tabular}

Анализ полученных данных указывает на сосуществование основных клинкерных минералов цемента с периклазом во всем исследуемом интервале температур, что позволяет использовать периклаз в качестве заполнителя для получения огнеупорного бетона.

Для получения бетона высокой прочности, плотности и однородности был проведен подбор оптимального гранулометрического состава заполнителя. Образцы-кубы размером $5 \times 5 \times 5 \mathrm{~cm}$ изготовлялись методом виброукладки из бетонной смеси с водотвердым отношением $\quad 0,08$. Оптимизация количественного соотношения смежных фракций заполнителя проводилась с помощью симплексно-решетчатого метода планирования эксперимента [8].

Для описания зависимости прочности бетона от количественного соотношения фракции заполнителя использовали полином неполного третьего порядка. По результатам полученных экспериментальных данных рассчитаны коэффициенты полинома, выражающего зависимость прочности и огнеупорности от количественного и гранулометрического соотношения фракций заполнителя.

Уравнения регрессии имеют вид:

$$
\begin{gathered}
Y \sigma=51,2 x_{1}+63,5 x_{2}+67,2 x_{3}+10,6 x_{12}-23,2 x_{13}-63,0 x_{23}+493,2 x_{123} \\
Y t=1580 x_{1}+1630 x_{2}+1650 x_{3}-20 x_{12}-260 x_{13}-440 x_{23}+5130 x_{123}
\end{gathered}
$$

По результатам выполненных расчетов и математической обработки результатов эксперимента построены

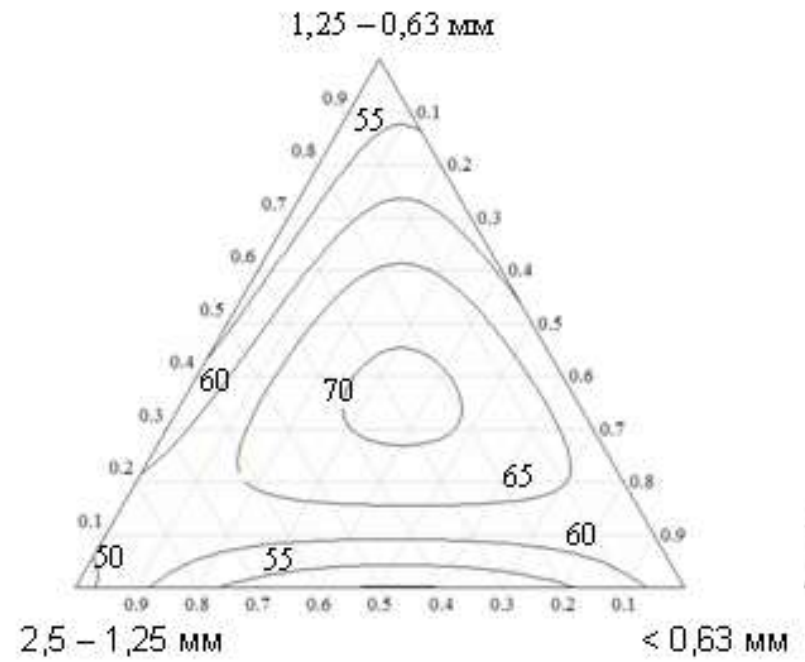

Рис. 2. Диаграмма «состав - прочность»

симплекс-диаграммы «состав - прочность» и «состав - огнеупорность» для огнеупорного бетона (рис. 2 и 3 ).

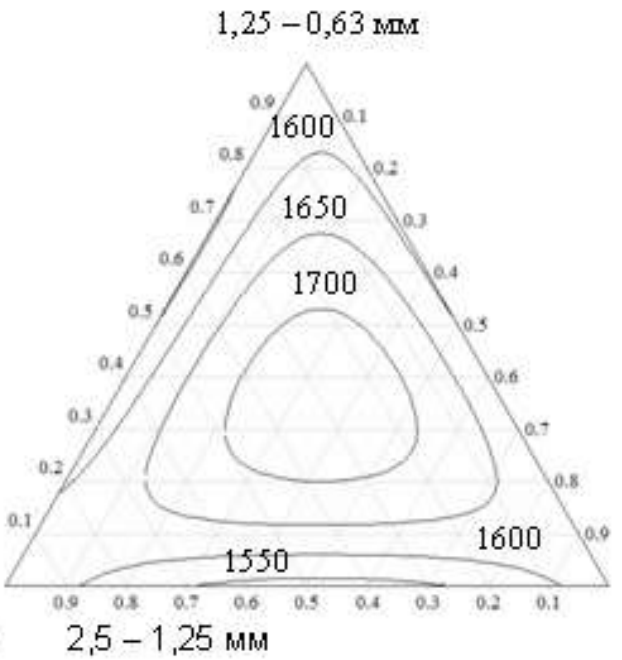

Рис. 3. Диаграмма «состав - огнеупорность» 
Из результатов расчета видно, что для получения бетона высокой прочности и огнеупорности необходимо брать трехфазную смесь заполнителя со следующим количественным соотношением размеров зерен:

фракция $(2,5-1,25)$ мм - $18-40$ масс. \%

$$
(1,25-0,63) \text { мм - } 27-44 \text { масс. } \%
$$

$$
<0,63 \text { мм - } 25-46 \text { масс. } \%
$$

Последующие исследования бетонов проводились с учетом оптимального гранулометрического состава заполнителя.

Образцы бетонов твердели и набирали прочность на воздухе. Через 1 сут твердения бетон имел прочность 21 МПа. Для определения стойкости полученного бетона к влиянию высокой температуры образцы бетона обжигали в криптоловой печи при температуре $1700-1750^{\circ} \mathrm{C}$ в течение трех часов. Охлаждение образцов проводилось вместе с печью. После обжига сколов, разрывов, трещин, проплавов и внешних изменений образцов не выявлено. Уменьшение объема образцов составляло $1,0 \%$. Прочность на сжатие образцов после обжига составляла 75,8 МПа.

$\mathrm{C}$ помощью рентгенофазового метода анализа был исследован бетон после обжига [6]. Результаты рентгенофазового анализа приведены на рис. 4.

Установлено, что основными фазами бетона являются: $\mathrm{MgO}\left(\mathrm{d} \cdot 10^{-10}=2,427\right.$; $2,103 ; 1,488 \mathrm{M}) ; \mathrm{BaAl}_{2} \mathrm{O}_{4}\left(\mathrm{~d} \cdot 10^{-10}=4,537\right.$; $4,383 ; 3,151 ; 2,608 ; 2,243 ; 2,193 ; 2,019 \mathrm{M})$; $\mathrm{Ba}_{3} \mathrm{Cr}_{2} \mathrm{O}_{6}\left(\mathrm{~d} \cdot 10^{-10}=3,236 ; 2,871 ; 2,359 ;\right.$ 2,144; 1,$961 ; \quad 1,717$ м), то есть взаимодействия между компонентами цемента и заполнителя при высоких температурах не происходит. По совокупности характеристик периклаз является перспективным заполнителем для получения огнеупорного бетона на основе алюмобариевого хромсодержащего цемента.

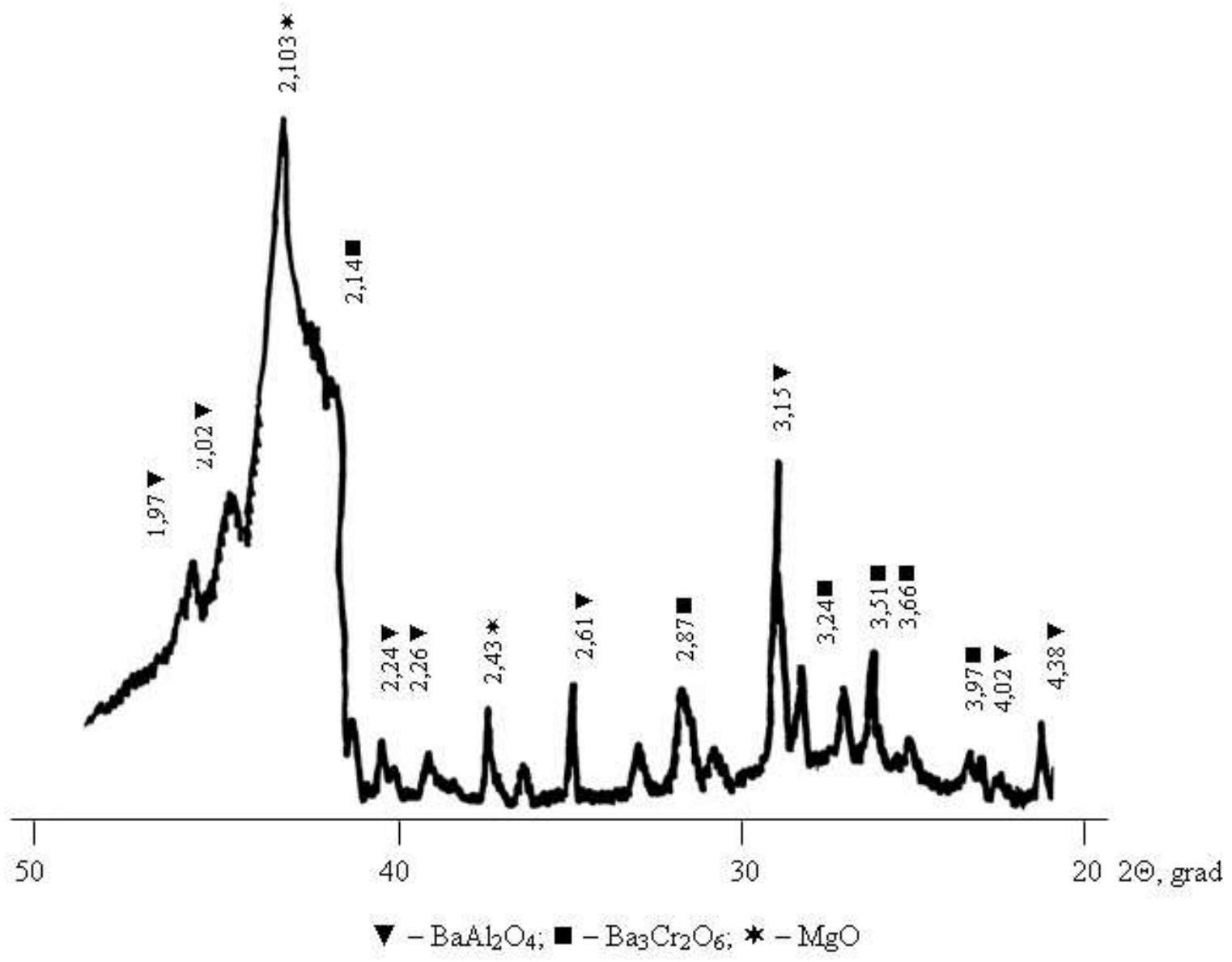

Рис. 4. Рентгенограмма образца бетона после термообработки 
Для определения шлакостойкости полученного бетона были использованы основной шлак ОАО «Алчевский металлургический комбинат» и кислый шлак ОАО «Запорожсталь». Для определения глубины пропитки шлаком из бетонной смеси были отпрессованы образцы в виде кубов с размером ребра 5 см с цилиндровым углублением диаметром 25 см и глубиной $30 \mathrm{~cm}$. Полученные тигли твердели на протяжении 3 суток в воздушных условиях. После этого расплавляли основной и кислый шлаки при температуре $1450^{\circ} \mathrm{C}$ на протяжении 2 час. После остывания тигли распиливали через центр углубления и оценивали глубину пропитывания. Установлено, что для основного шлака глубина разъедания составляет 2,8 мм, для кислого шлака 2 мM.

Таким образом, на основании проведенных теоретических расчетов и экспериментальных исследований установлено, что полученный бетон на основе алюмобариевого хромсодержащего цемента и заполнителя периклаза является высокопрочным, огнеупорным, шлакостойким конструкционным материалом и может быть рекомендован к использованию в качестве футеровки в высокотемпературных агрегатах различных отраслей промышленности.

\section{Список литературы}

1. Огнеупорные материалы. Структура, свойства, испытания [Текст]: справочник / Й. Алленштейн, П. Барта, Х. Бартель [и др.]; под ред. Г. Роучка, Х. Вутнау; пер. с нем. И.Г. Очаговой. - М.: Интермет Инжиниринг, 2010. - 392 с.

2. Кащеев, И.Д. Химическая технология огнеупоров [Текст] / И.Д. Кащеев, К.К. Стрелов, П.С. Мамыкин. - М.: Интермет Инжиниринг, 2007. - 752 с.

3. Огнеупоры для промышленных агрегатов и топок [Текст]: справочник: в 2 кн. Кн. 1. Производство огнеупоров / И.Д. Кащеев, В.Г. Адеева, М.Г. Ладыгичев [и др.]; под ред. И.Д. Кащеева.. - М.: Интермет Инжиниринг, 2000. - 663 с.

4. Alumina cement with spinel / [G.N. Shabanova, A.N. Korogodskaya, N.K. Vernigora at al.] // 17 International Baustofftagung. 23-36 September, 2009. - Tagungsbericht. - Band 1. Weimar, Bundesrepublik, Deutschland. - Weimar, 2009. - S. 573-578.

5. Бутт, Ю.М. Практикум по химической технологии вяжущих материалов [Текст] / Ю.М. Бутт, В.В. Тимашев. - М.: Высш. шк., 1973. - 503 с.

6. Горшков, В.С. Вяжущие, керамика и стеклокристаллические материалы: Структура и свойства [Текст]: справоч. пособие / В.С. Горшков, В.Г. Савельев, А.В. Абакумов. - М.: Стройиздат, 1994. - 584 с.

7. Строение трехкомпонентной системы $\mathrm{BaO}-\mathrm{Al}_{2} \mathrm{O}_{3}-\mathrm{Cr}_{2} \mathrm{O}_{3}$ в области субсолидуса [Текст] / А.Н. Корогодская, Г.Н. Шабанова, В.Ю. Гофман, О.А. Гамова // Зб. наук. праць ВАТ «УкрНДІВогнетривів імені А.С. Бережного». - Харків: Каравела, 2008. - № 108. - С. 147-155.

8. Кафаров, В.В. Оптимизация эксперимента в химии и химической технологии [Текст] / В.В. Кафаров, С.Л. Ахназарова. - М.: Высшая школа, 1978. - 319 с.

Ключевые слова: огнеупорный бетон, алюмобариевый хромсодержащий цемент, заполнитель, периклаз, шлакоустойчивость, прочность.

\section{Аннотации}

Наведено результати розроблення вогнетривкого бетону на основі алюмобарієвого хромвмісного цементу. Встановлено, що за своїми фізико-механічними й технічними 
властивостями розроблені бетони не поступаються випаленим вогнетривким виробам, що дає змогу рекомендувати їх для широкого використання як футеровок у високотемпературних агрегатах різноманітних галузей промисловості.

Представлены результаты разработки огнеупорного бетона на основе алюмобариевого хромсодержащего цемента. Установлено, что по своим физико-механическим и техническим свойствам разработанные бетоны не уступают обжиговым огнеупорным изделиям, что дает возможность рекомендовать их для широкого использования в качестве футеровок в высокотемпературных агрегатах различных отраслей промышленности.

In this article the results of development of refractory concrete on the base of the aluminabarium chromium-containing cement are presented. It was founded that on their physical, mechanical and technical properties these concretes are like fired refractory products and this makes it possible to recommend these concretes for wide use as linings in high-temperature units in various industries. 